\title{
A Colorimetric Method for Studying the Dissociation of Oxyhæmocyanin suitable for Class Work.
}

\author{
By \\ C. F. A. Pantin, M.A., \\ Assistant Physiologist at the Plymouth Laboratory, \\ And \\ Lancelot T. Hogben, M.A., D.Sc., \\ Ray Lankester Investigator.
}

With 6 Figures in the Text.

\section{INTRODUCTION}

Тнат hæmocyanin can act as a carrier of oxygen may now be regarded as established beyond doubt, though, as in the case of hæmoglobin, in some of the lower forms the significance of this property to the normal respiratory processes of the organism is not yet clear. The determinations of Winterstein (1908) on the oxygen capacity of the blood of invertebrates endowed with and devoid of hæmocyanin, and the more recent observations of Dhéré (1916-21), who has correlated the oxygen capacity of the blood of species which possess hæmocyanin with the blood copper content, leave no doubt regarding the former issue. Dhéré, Craifalneau and Quagliariello have respectively made observations on the chemical properties of the hæmocyanin of crustacea, pulmonates and cephalopods : Alsberg and Clark have studied the hæmocyanin of Limulus. But as yet there has been little detailed work on the physical chemistry of its respiratory property. Redfield and Hurd (1925) have plotted the dissociation curve of the oxyhæmocyanin of Limulus and Loligo by a colorimetric method; and in this laboratory the Stedmans (1925) have performed a great service by comparing the dissociation curve of several genera of decapod crustacea by direct measurement with van Slyke's technique. But so far as we are aware no data have yet been published with reference to the effect of hydrogen ion concentration, salinity, temperature and other factors, which are known to influence the dissociation curve of hæmoglobin, on the oxidation of hæmocyanin.

By the use of a very simple device, to be described, observations made 
by the present authors shew that the dissociation of hæmocyanin under these conditions is influenced in a manner closely analogous to that of hæmoglobin; and as the physical chemistry of hæmoglobin necessitates the use of a considerable amount of elaborate and expensive apparatus, the method which we have explored, primarily with a view to class work, provides, we believe, an admirable means of illustrating some essentials of the general physiology of respiratory pigments with the minimum expenditure of time, equipment and technique. We have therefore thought it desirable to issue a detailed account of the procedure which may prove acceptable to others who are concerned with the teaching of zoology on experimental lines. For this reason we have ventured to set forth the details of the method rather fully, so that no difficulty should be experienced in carrying it out. At the same time the observations which we have recorded may, it is hoped, suggest fields of further enquiry by the more direct but laborious procedure for the study of oxygen transport by animal pigments.

\section{Method.}

As Redfield and Hurd have pointed out, the fact that reduced hæmocyanin is colourless renders it possible to estimate the degree of oxidation by a colorimetric method which is not applicable to the case of hæmoglobin. Subject to certain safeguards which will be mentioned later, the percentage saturation may be directly determined by comparison with known dilutions of blood in contact with air, without recourse to the more elaborate procedure adopted by these authors, i.e. the preparation of colour standards by mixture of the reduced and oxidised pigment.

Since the oxygen content of the atmosphere is constant, the oxygen pressure may be varied directly by exposing the blood to air at reduced pressure without the customary preparation of analysed mixtures of gases. Thus the only apparatus required besides a series of uniform tubes for the colour standards is a manometer and pump provided with a stopcock. For the latter purpose a filter pump amply suffices to lower the gas pressure to a value not differing significantly from the pressure of water vapour at the given temperature, that is to say the partial pressure of oxygen can thereby be reduced to zero within the limits of experimental error. The apparatus is illustrated in Fig. 1. Large quantities of blood containing hæmocyanin can be obtained readily from the larger decapod crustacea, such as the crawfish, Palinurus; the lobster, Homarus ; or the crab, Cancer. The method is also applicable for the study of molluscan blood, for which purpose the edible snail, Helix, is most convenient for laboratory work.

Preparation of serum. Palinurus was found to provide the most favourable material as a crustacean type. To prevent movement it is 
convenient to secure the animal lengthwise to a stout rod applied to the ventral surface, with the head uppermost. The last abdominal tergum is removed so that the blood may drain into a vessel : it is well to cut the aorta, but if this is done care should be taken on no account to include the rectum, the contents of which will pollute the blood. The blood, as is well known, coagulates with phenomenal rapidity. The coagulum is ground with sand in a mortar, the exudate being filtered or cleared by centrifuging. The yield should be about $60 \mathrm{cc}$. for a medium-sized crawfish. After shaking with air the clear serum is of a dark blue tint by reflected light. Occasionally individuals are found which have little hæmocyanin in their blood: these cannot be used for experiment. The same serum should be used both for the preparation of the comparator and for whatever subsequent operations are to be performed. If a few drops of toluol are added the serum will keep for several days; but after twenty-four hours' standing a peculiar form of spontaneous reduction occurs. The colour disappears, but is rapidly restored to its original intensity on shaking in the presence of air. The precise nature of this change has not been determined. It will be mentioned later that the character of the dissociation curves obtained with stale serum was not precisely identical with those derived from fresh blood. This would appear to be due, partly at least, to the fact that, though well-buffered, the blood becomes more acid on standing.

To obtain blood from snails the animal is first anæsthetised or killed with chloroform, the shell is chipped off above the mantle cavity, into which an incision is made. The blood is allowed to drain off without coming into contact with the yellow slime. In the case of hibernating snails it is sufficient to make an incision in the foot. The yield is about 1 cc. per individual. On being shed the blood is of an opalescent blue tint. It should be shaken with sand and filtered or centrifuged.

Preparation of colour standards. For making the comparator a series of uniform test tubes of thick glass (preferably about $1.8 \mathrm{~cm}$. bore) are mounted in a rack as for $\mathrm{pH}$ determination. As reduced crustacean blood displays a pale orange tint owing to the presence of an ether-soluble pigment, the serum cannot be simply diluted with water. A little serum is shaken up for at least ten minutes in a tube thoroughly exhausted, as described below. A very dilute solution of orange $G$ with a trace of logwood and Indian ink gives a perfect match for the reduced serum by reflected light, and can be prepared in a few minutes. This solution is used for diluting the serum from $0-100$ per cent in 10 per cent stages. A slight opalescence may appear after shaking the exhausted serum, and it is well therefore not to prepare the diluting solution till the serum has been shaken for the time stated, though two minutes' shaking of a small quantity such as 5 c.c. in a fairly large test tube should suffice 
for equilibration. For the colour standards 5 c.c. of each solution are sufficient. The experimental serum is compared with the diluted solutions by reflected light: the same diluting solution will not serve for use with artificial light. In preparing colour standards for the snail's blood a very dilute solution of orange $\mathrm{G}$ with a faint trace of methylene blue is satisfactory.

\section{Apparatus}

The arrangement of the apparatus is illustrated in Fig. 1. A manometer is connected by a T-piece with a filter pump $(F)$ and a rubber stopper fitting into a test tube $(E)$ of the same bore as those used for the

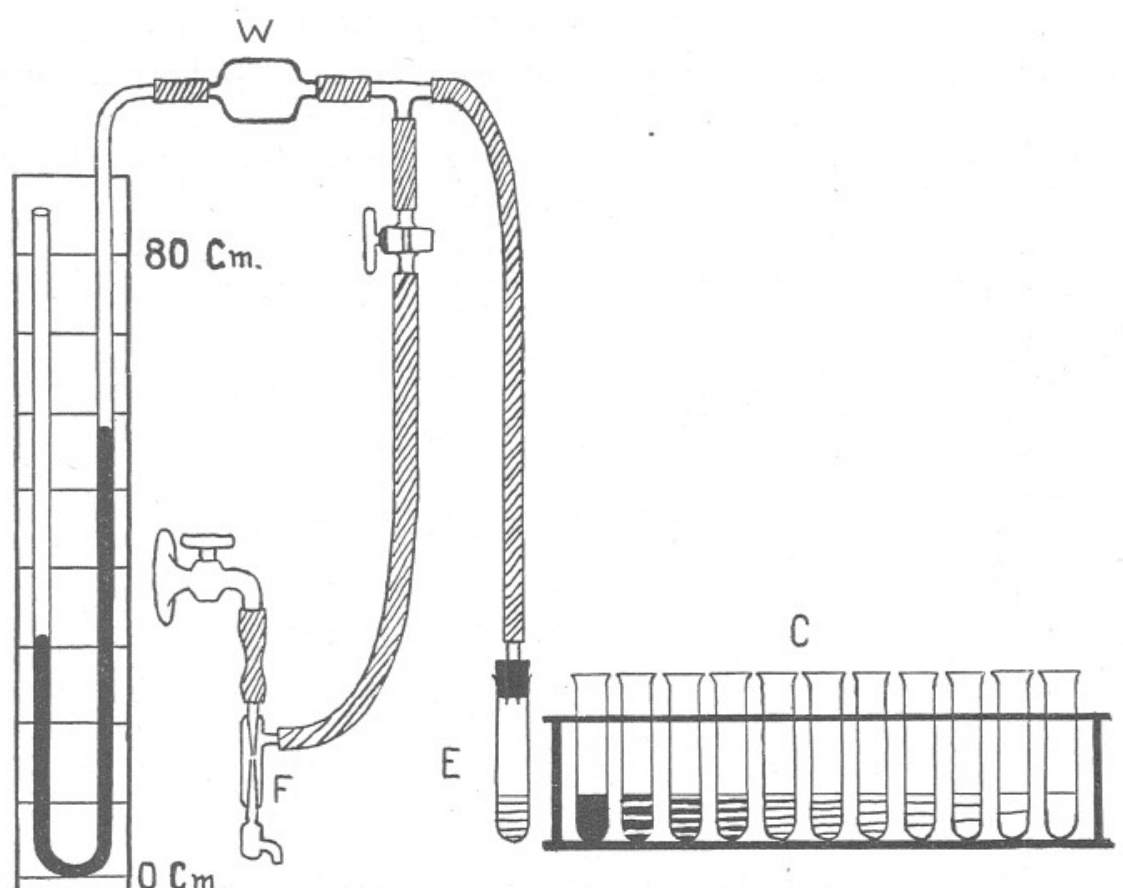

FIG. 1.-Apparatus for colorimetric determination of percentage of oxidised hæmocyanin. W. Water trap. E. Tube for experimental serum. F. Filter pump. C. Colour standards.

colour standards. A glass stopcock is interposed between the filter pump and the T-piece, and it is advisable to insert in the position indicated a water trap $(W)$ which can be made conveniently from a large pipette. Five cubic centimetres of serum are placed in the test tube which is then exhausted. The stopcock is turned and the tube shaken till the serum is completely reduced. This need not occupy more than five minutes, 
in the case of crustacean blood rather less. The stopcock is then loosened so that the system is refilled with normal air. If this is done there is no danger of error at low pressures in consequence of the oxygen evolved. Such error would in any case be very minute owing to the low oxygen capacity of the blood and the relatively large internal volume of the apparatus. In subsequent operations in which comparison is made on the same sample at different pressures, the oxygen tension is given by $0 \cdot 21(b-v-m), b$ being the observed barometric pressure, $v$ the vapour pressure of water for the temperature at which the experiment is carried out, $m$ the manometer reading, and $0 \cdot 21$ the proportion of oxygen in atmospheric air.

\section{The Dissociation Curve of Crustacean Blood.}

Since colorimetric methods are often regarded as involving a large personal error, we have not attempted to use the method outlined above until satisfied that our independent observations were consonant with one another and with those of other workers in the laboratory not conversant

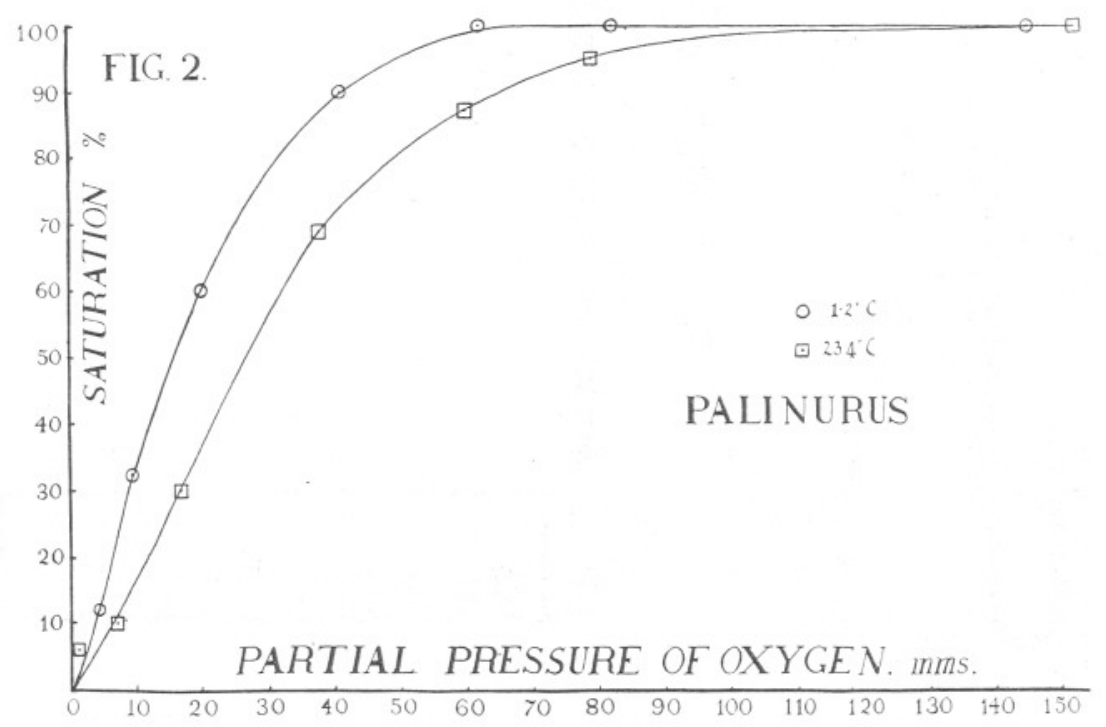

with the object of the experiment. Furthermore, in all experiments one of us recorded observations (including tensions) of which the other, responsible for the colorimetry, was kept in ignorance. For Palinurus the limits of error were found to be well within 5 per cent : in the case of Helix the error was perhaps a little greater, possibly on account of the greater time required to complete equilibration. Having satisfied ourselves both as to the accuracy of the method and its serviceability for persons inexperienced in colorimetry, we have employed it to investigate 
some aspects of the physical chemistry of hæmocyanin which are eminently suitable for class experiments. These include the effect of temperature, hydrogen ion concentration and salinity on the character of the dissociation curve of oxyhæmocyanin. Since a six or seven point curve can be completed on the same sample within half an hour, the method should not make undue demands upon the time of the student.

Effect of temperature. In Fig. 2 are given two curves, one representing the dissociation of the hæmocyanin of Palinurus equilibrated at room temperature, the other based on the same specimen equilibrated by shaking in a large vessel of ice-cold water. At the lower temperature the affinity of the hæmocyanin for oxygen at low tensions is considerably increased in a manner precisely analogous to the well-established effect of temperature on the dissociation curve of hæmoglobin. However, it is to be noted that, while the points on each curve are ideally consistent, both curves are flatter than might be expected, compared with those obtained

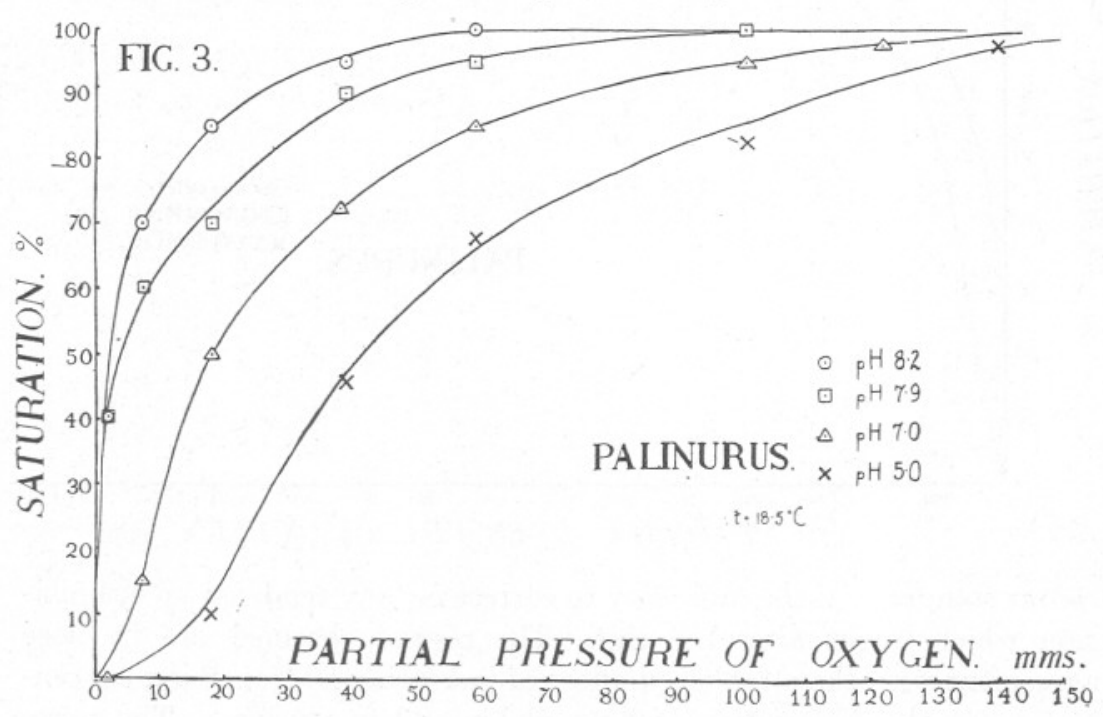

from fresh serum (Figs. 3 and 4). The serum used in the experiments on the influence of temperature had stood for twenty-four hours: as already remarked, blood of Palinurus becomes more acid on standing.

Effect of hydrogen ion concentration. No data are as yet available, to our knowledge, with reference to the isoelectric point of crustacean hæmocyanin ; but the determinations of Quagliariello on the hæmocyanin of Octopus lead one to anticipate the possibility of varying the $\mathrm{pH}$ on the alkaline side of the isoelectric point over a much wider range than can be done in the case of hæmoglobin. The buffer action of Palinurus blood is fairly considerable, and as the blood requires little dilution to 
eliminate the bluish tint by transmitted light, colorimetric determination of $\mathrm{pH}$ may be made without any serious error arising, subject to correction for protein content. In Fig. 3 are depicted four curves on the same specimen of fresh serum, one made more alkaline to $\mathrm{pH} 8 \cdot 2$ by addition of one drop per c.c. of a double strength of Palitzch's boric acid-borate mixture, two others being made more acid than normal serum ( $\mathrm{pH} 7 \cdot 9$ ) by addition in one case of one drop of acidified saturated sodium phosphate to 5 c.c. (giving $\mathrm{pH} 7 \cdot 0$ ) and in the other case of a corresponding quantity of saturated sodium acetate acidified with acetic acid (giving a $\mathrm{pH} 5 \cdot 0$ ). In comparing each sample it is best to treat the

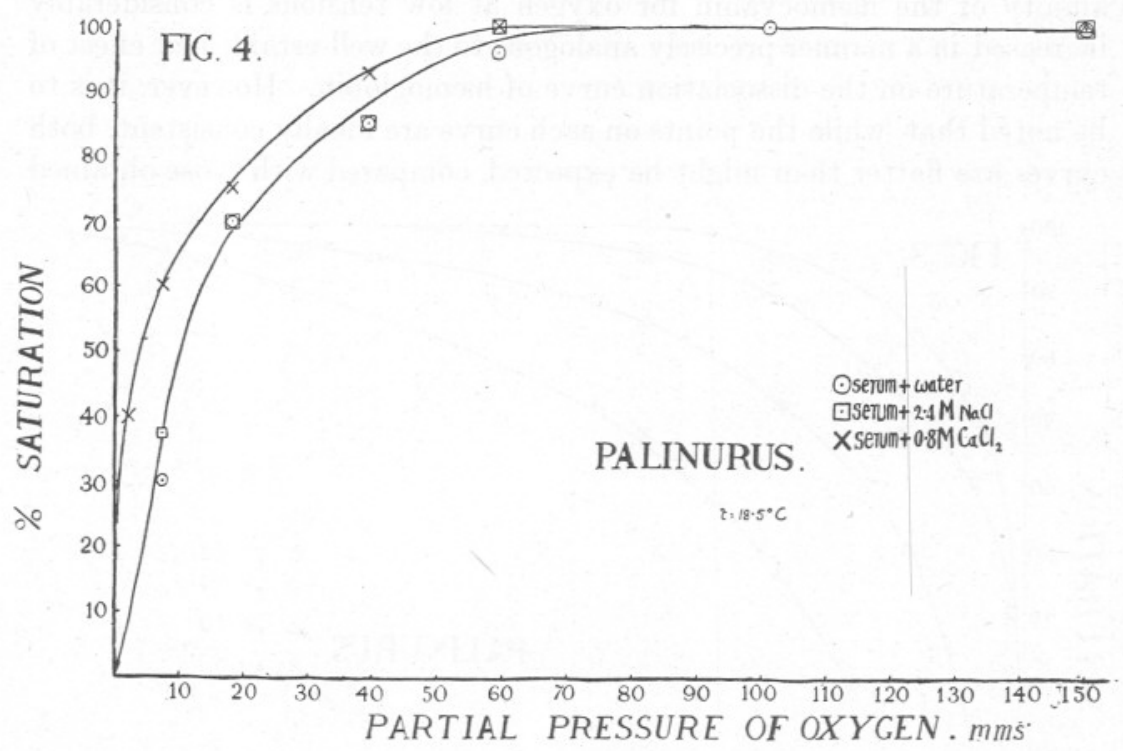

colour standards in the same way to correct for any tendency to coagulation which might alter the tint. The results obtained are in close agreement with the established effect of increasing hydrogen ion concentration on the dissociation of hæmoglobin at low tensions. The curve marked $7 \cdot 0$ is subject to a protein + salt error of about $+0 \cdot 4$.* $^{*}$

Effect of salinity. The effect of salinity may be investigated by diluting the serum half and half with water or saline solutions of various strengths, due regard being paid to hydrogen ion concentration. In comparing the action of salts on the dissociation of crustacean and mammalian blood

* Protein error of diluted Palinurus blood was approximately determined as follows : 1 cc. of blood is added to each of two tubes; one of these is made up to 5 cc. with distilled water, the other to $5 \mathrm{cc}$. with a strong buffer of known $\mathrm{pH}$. The $\mathrm{pH}$ is then determined by adding indicator in the usual manner, the first tube being placed behind the standard tube to allow for the colour of the serum. The apparent $\mathrm{pH}$ of the buffered solution is subtracted from the known $\mathrm{pH}$ of the strong buffer. 
it is well to bear in mind that the absolute concentration of saline constituents.in the former is at least three times as great as in the latter. A corresponding series of colour standards are made for these experiments. Fig. 4 shows the effect of certain salts at $\mathrm{pH} 7 \cdot 9$.

Dilution to half strength with a $2.4 \mathrm{M}$. solution of sodium chloride was not found to have a significant effect on the dissociation curve of Palinurus, as compared with the normal curve, and also with the curve of serum diluted with water. For the reason stated above this need not be taken to indicate a characteristic difference between hæmoglobin and hæmocyanin. On mixing equal quantities of the same sample of serum with $0.8 \mathrm{M}$. solutions of calcium chloride there was an appreciable shift. The action of Lanthanum chloride was subsequently tested. However, no appreciable effect was observed at concentrations ( $0.00025 \mathrm{M}$.) even near to that at which coagulative changes occurred in the blood. In the case of Maia, Homarus, and Cancer, experiments by one of us (L. T. H.) shewed a decided steepening of the dissociation curve of serum diluted 50 per cent with $2 \mathrm{M}$. $\mathrm{Na}, \mathrm{Li}$ and $\mathrm{K}$ chlorides and $\mathrm{M} \mathrm{Ca}, \mathrm{Mg}$ and $\mathrm{Sr}$ chlorides as compared with that of serum diluted 50 per cent with water.

\section{The Dissociation Curve of Molluscan Blood.}

While spectroscopic observations by Dhéré and others make it almost certain that the hæmocyanins of different groups are not identical, one may doubt whether the character of the dissociation curves of the Arachnid Limulus and the Cephalopod Loligo reinforces this conclusion, as Redfield and Hurd suggest. The dissociation curve of acidified crustacean blood closely approaches that of Loligo as recorded by Redfield and Hurd ; while that of the normal serum is more like Redfield and Hurd's curve for Limulus (Fig. 6). We have therefore made a few experiments on another molluscan genus, Helix, with a view to ascertaining how far the difference between Limulus and Loligo might not be due to differences in hydrogen ion concentration of the blood of the two animals. No sufficient quantity of Loligo blood was obtainable to reinvestigate its dissociation curve; but a single determination of the $\mathrm{pH}$ of the blood gave a value of about 5.4-5.6 as contrasted with 7.9-8.0 for the blood of Palinurus. The first curve which was plotted for the blood of Helix aspersa proved to be of the steep type characteristic of Limulus and Palinurus. The $\mathrm{pH}$ of snail's blood ( $H$. aspersa) is about $8 \cdot 7$, and the curve is a little flatter than the correspondingly alkaline curve for Palinurus; and it at first seemed likely that by acidifying the blood a condition approximating to that of Loligo would be obtained. In this surmise we were, however, disappointed; but the experiments performed brought out two points of some general interest. The first is the extraordinary extent to which 
the snail's blood is buffered, especially in view of the observations of Collip and of Parsons and Parsons on the alkali reserve of the blood of invertebrates. In one experiment five drops of a saturated sodium phosphate solution acidified with concentrated hydrochloric acid to $\mathrm{pH} 4$ when added to 5 c.c. of normal blood ( $\mathrm{pH} 8 \cdot 7$ ) only reduced it to $\mathrm{pH} 8 \cdot 2$. The second point is illustrated in Fig. 5. The dissociation curve of the snail's hæmocyanin was not found by this method to be affected appreciably by considerable variation in hydrogen ion concentration. Indeed the points

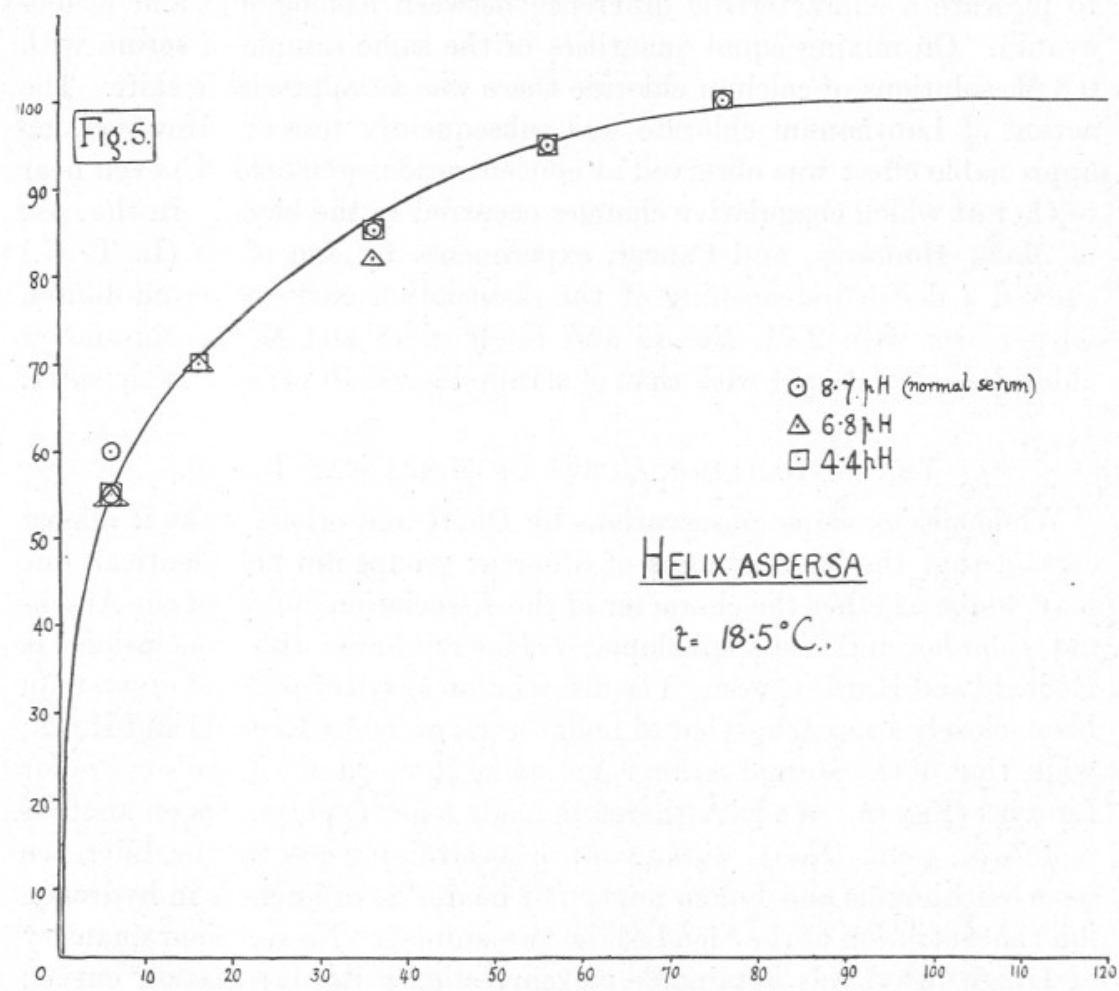

obtained from blood acidified to $\mathrm{pH} 4.4$ were consistent with the curve for normal serum; and closely located points were obtained when the blood was made alkaline to approximately $\mathrm{pH} 10.5$ with sodium carbonate. There seems to be a possible analogy between these facts and data given by Clark on the oxidation and reduction of certain simple organic compounds (e.g. hydroquinone and methylene blue). In these cases within a specified range of hydrogen ion concentration the oxidation-reduction potential of 50 per cent oxidation varies with the $\mathrm{pH}$, but below a certain degree of acidity it is little affected.

It has been shown by Parsons and others that hæmoglobin has an im- 
portant buffering action in relation to the transport of carbon dioxide, and more recent observations of Parsons and Parsons indicate that hæmocyanin may have an analogous function. The well-known action of the hydrogen ion upon the dissociation of hæmoglobin follows from Le Chatelier's principle, on the assumption that oxy-hæmoglobin is a stronger acid than the reduced form. The similar effect of acidity on the dissociation of crustacean hæmocyanin would therefore appear to reinforce the conclusions of Parsons and Parsons regarding the importance of hæmocyanin to carbon dioxide transport, and would lead one to anticipate that oxyhæmocyanin is a stronger acid than hæmocyanin itself. In

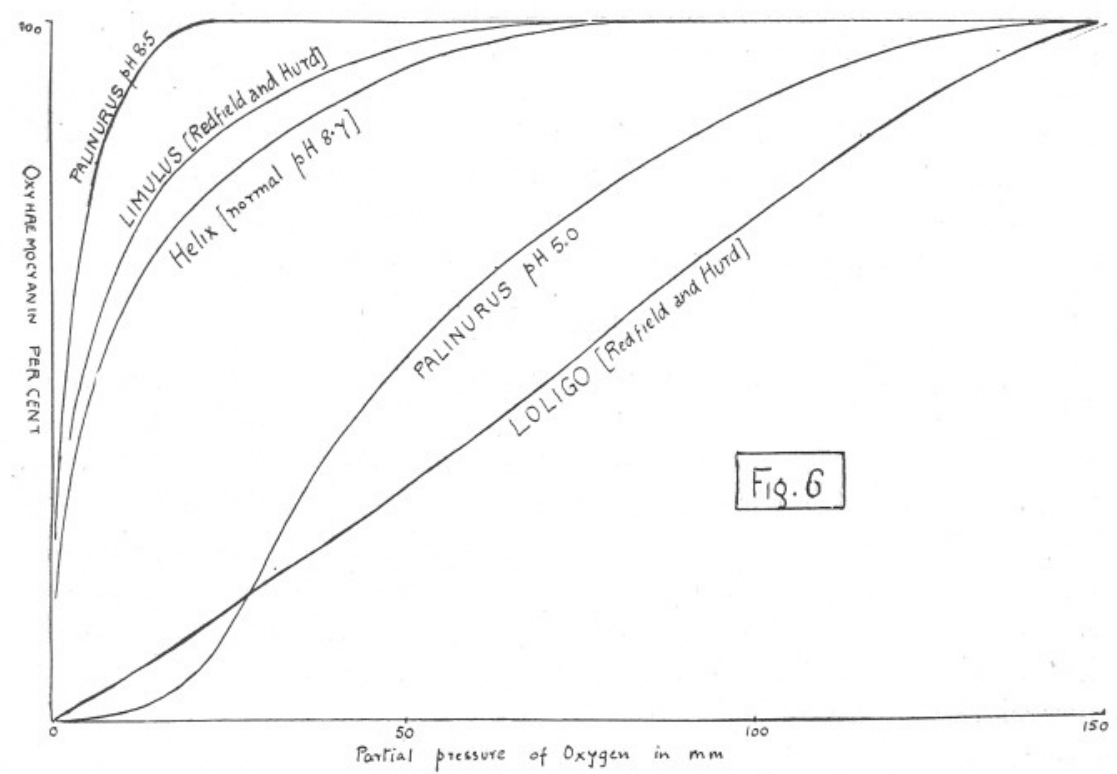

FIG. 6.-Dissociation of oxyhæmocyanins of Limulus, Helix, and Loligo compared with that of Palinurus at $\mathrm{pH} 8 \cdot 5$ and $\mathrm{pH} 5 \cdot 0$.

the case of the snail-within physiological limits-we should then conclude in the first place that the oxygen-combining power of its hæmocyanin does not facilitate the buffer action. The coincidence of the curves implies either that oxyhæmocyanin is not in this case significantly more acidic than its reduced form, or else that both are so little, or so completely, dissociated as to have no appreciable buffer action. In other words, the buffering action of the snail's hæmocyanin, if it has any such action, is not different in kind from that of other blood proteins. It may be well to note in this connexion that both in the case of crustacea and pulmonates, whatever may be true of Limulus and Cephalopods, hæmocyanin does not by any means represent the entire protein content of the blood.

NEW SERIES.-VOL. xiII. No. 4. ocTober, 1925. 
The newly shed blood of the snail appears to be completely oxidised; and it remains to be proved that it fulfils a respiratory function in relation to oxygen transport, though Dhéré's observations shew clearly that it is a reversibly oxidisable pigment. On the other hand in crustacea the hæmocyanin of freshly shed blood is often almost completely reduced. Until more attention has been paid to control of hydrogen ion concentration it is perhaps premature to conclude from the observations of Redfield and Hurd that the hæmocyanins of Limulus and Loligo are very different or to infer from those of Stedman and Stedman that the hæmocyanins of all the decapod crustacea are identicale (cf. Fig. 6). But it would seem most probable that the hæmocyanin of the snail differs more profoundly from that of Loligo and of Palinurus than do the hæmocyanins of the last two from one another. It should, however, be remembered that it is quite possible that the effect of other kations may have to be taken into account. So that a satisfactory demonstration of the identity or otherwise of the hæmocyanins can only be obtained from pure solutions of the isolated pigments under properly controlled conditions.

\section{SUMMARY.}

1. A simple colorimetric method for plotting the dissociation curve of hæmocyanin is indicated. The limits of error are within 5 per cent. The simplicity of the method commends it for laboratory class work.

2. The effect of hydrogen ion concentration on the dissociation of the hæmocyanins of the crustacean Palinurus and the pulmonate Helix have been compared. In the snail change of hydrogen ion concentration over a wide range was not found to affect the dissociation of the hæmocyanin : in the crustacean there is a marked effect similar to that seen in the dissociation of hæmoglobin.

3. The similarity of crustacean hæmocyanin to hæmoglobin is also seen in that increasing temperature depresses the dissociation curve. The effects of certain salts upon hæmocyanin have also been recorded.

\section{REFERENCES.}

Alsberg and Clark. J. Biol. Chem. 8. 1910. Ibid. 19. 1914.

Collip. J. Biol. Chem. 44. 1920.

Cratfalneau. Boll. Soc. Nat. Napoli. 31. 1918.

Dни́ré. J. Physiol. et Pathol. gen. 16-20. 1916-20.

Henze. Zeit. f. physiol. Chem. 33-43.

Parsons and Parsons. J. Gen. Physiol. 6. 1923.

Quagliariello. Pubbl. St.Zool. Napoli (Ric. physiol. e chim biol. 1).1922.

Redfield and Hurd. Proc. Nat. Acad. Sci. 11. 1925.

Stedman and Stedman. Biochem. J. 1925. (In the press.)

Winterstern. Biochem. Zeitschr. 19. 1908. 